\title{
X-Ray Powder Diffraction: Why Not Use CuKB Radiation?
}

\author{
Hans Hermann Otto \\ Materialwissenschaftliche Kristallographie, Clausthal University of Technology, Clausthal-Zellerfeld, Germany \\ Email: hhermann.otto@web.de
}

How to cite this paper: Otto, H.H. (2018) X-Ray Powder Diffraction: Why Not Use $\mathrm{Cu} K \beta$ Radiation? Journal of Analytical Sciences, Methods and Instrumentation, 8, $37-47$.

https://doi.org/10.4236/jasmi.2018.83004

Received: August 16, 2018

Accepted: September 9, 2018

Published: September 12, 2018

Copyright (c) 2018 by author and Scientific Research Publishing Inc. This work is licensed under the Creative Commons Attribution International License (CC BY 4.0).

http://creativecommons.org/licenses/by/4.0/

(c) (i) Open Access

\begin{abstract}
$\mathrm{Cu} K \beta$ radiation with a wavelength of $\lambda=1.3923 \AA$ is recommended for crystal structure determination from $X$-ray powder diffraction using the Rietfeld method. A highly sensitive image plate detector is able to collect enough intensity to record a brilliant $X$-ray powder pattern in a reasonable time, compared to $\mathrm{Cu} K \alpha_{1}$ radiation used today. Especially atomic displacement coefficients could be determined more precisely with the much greater number of reflections recorded. A double-radius Guinier camera attached to a micro-focus rotating anode tube ensures increased brilliance besides high resolution. A simple construction specification is presented to make smart cylindrically bent $\mathrm{Ge}(111)$ or $\mathrm{Si}(111) X$-ray monochromators that deliver focused $\mathrm{Cu} K \beta$ radiation. The highly linear response of image plate detectors allows removing of fluorescence radiation simply as background of the pattern. The proposed equipment is a cost-efficient alternative to a liquid gallium-metal-jet $X$-ray source with maximum power load and a similar wavelength of $\lambda\left(\mathrm{Ga} K \alpha_{1}\right)=1.34013 \AA$.
\end{abstract}

\section{Keywords}

$X$-Ray Diffraction, Rietfeld Analysis, $\mathrm{Cu} K \beta$ Radiation, Guinier Method, Focusing Monochromators, $X$-Ray Diffraction Equipment Construction

\section{Introduction}

By application of the Rietfeld method for crystal structure determination on powders using $\mathrm{Cu} \mathrm{Ka}_{1}$ radiation the limiting data set of reflections accessible considerably influenced the reliability of the structure parameters. Therefore, sometimes ago we constructed a double-radius Guinier diffractometer that operates with $\mathrm{MoK \alpha} \alpha_{1}$ radiation diffracted from a self-constructed $\mathrm{Ge}(220)$ monochromator [1]. However, in case of yttrium-based superconductors, the fluo- 
rescence radiation from that element contributes much to the background. Even if the results achieved were absolutely satisfactory and a substantial improvement, an alternative approach is to be recommended and explained here: the application of extended laboratory collected $\mathrm{Cu} K \beta$ data sets for Rietfeld structure refinement. Some years ago, preliminary measurements were done by a coworker and published in his dissertation [2]. The present author recommended a more routine use of $\mathrm{Cu} K \beta$ radiation, in contrast to a more expensive gallium-metal-jet $X$-ray source [3], on the basis of some improvements, which are reported in this article. This improvements cover, besides a well constructed monochromator, a different camera setting of subtractive chromatic dispersion, and a stripe by stripe read out routine of the imaging plate to increase the intensity and open the possibility for texture diagnosis and correction. The publication of this contribution is encouraged by several thousand reads of a pre-published version in Researchgate.net.

\section{Estimate of Reflection Numbers}

One can roughly estimate the number of reflections as being inversely proportional to the third power of the applied wavelength $\lambda$. With the $\mathrm{Cu} K \alpha_{1}$ to $\mathrm{Cu} K \beta$ wavelength ratio one yields the factor

$$
\left[\lambda\left(\mathrm{CuK} \alpha_{1}\right) / \lambda(\mathrm{Cu} K \beta)\right]^{3}=(1.5406 / 1.3922)^{3}=1.355 .
$$

By applying $\mathrm{Cu} K \beta$ radiation in contrast to $\mathrm{Cu} K \alpha_{1}$ about $35 \%$ more reflections can be recorded. This percentage may be somewhat higher in the case of triclinic symmetry. A Rietfeld analysis performed with this considerably increased reflection number allows a markedly higher reliability. If the powder pattern is taken up to $2 \theta=100^{\circ}$, the limiting reciprocal lattice plane is $d_{\text {lim }}=0.9087 \AA$, compared to $d_{\text {lim }}=0.7093 \AA$ for single crystal data recorded up to $2 \theta=60^{\circ}$ using $\mathrm{MoKa}$ radiation.

\section{Prerequisites}

In order to work with $\mathrm{Cu} K \beta$ radiation for crystal structure determination atomic scattering factors as well as attenuation factors must be available. As early as 1967, Hazell [4] calculated anomalous scattering corrections $\Delta f$ and $\Delta f^{\mathbb{t}}$ for $K \beta$ radiation of different anode materials, covering the elements of $Z=10(\mathrm{Ne})$ to $Z$ $=98$ (Cf). All data relating to $\mathrm{Cu} K \beta$ radiation, as well as to the $\mathrm{Ga} K \alpha_{1}$ one that is coming, should be collected or precisely calculated, and then reported in the International Tables for $X$-ray Crystallography.

Now we consider the obviously disadvantageous $\mathrm{Cu} K \beta$ to $\mathrm{Cu} K \alpha_{1}$ intensity ratio. However, the separation of solely the $K \alpha_{1}$ radiation leads due to the complex structure of the $\mathrm{Cu} K$ spectrum (Table 1) [5] to a considerable reduction of its originally high intensity in comparison to the $K \beta$ line. In this way, the naturally unfavorable intensity ratio of $\mathrm{I}(K \beta) / \mathrm{I}\left(K \alpha_{1}\right) \approx 1 / 5$ can be markedly improved to $1 / 3$ or even $1 / 2$. 
Table 1. The $K \alpha$ and $K \beta X$-ray emission spectrum of copper after Deutsch et al. [5] Conversion factor $\lambda(\AA)=12.39842 / E(\mathrm{keV})$. Intensities of the $K \beta$ lines are given in arbitrary units by [5] and were converted to $I(\mathrm{Cu} K \alpha) / I(\mathrm{Cu} K \beta)=7.5: 2=100: 26.67$.

\begin{tabular}{|c|c|c|c|c|c|}
\hline Notation & Wavelength $(\AA)$ & \multicolumn{2}{|c|}{ Relative Intensity } & \multicolumn{2}{|c|}{$(\Delta \lambda / \lambda) \times 10^{4}$} \\
\hline$K \beta_{2}^{\prime \prime}$ & 1.391337 & 4.0 & 0.77 & 8.315 & \multirow{5}{*}{4.123} \\
\hline$K \beta_{1}^{\prime \prime}$ & 1.391753 & 18.0 & 3.48 & 5.197 & \\
\hline$K \beta_{1}$ & 1.392219 & 74.1 & 14.32 & 4.087 & \\
\hline$K \beta_{3}$ & 1.392593 & 34.0 & 6.67 & 3.965 & \\
\hline$K \beta$ & 1.393541 & 7.4 & 1.43 & 8.846 & \\
\hline$\Sigma$ Intensity & \multicolumn{5}{|c|}{26.67} \\
\hline Satellite & 1.534753 & \multicolumn{2}{|c|}{1.60} & & \multirow{3}{*}{2.930} \\
\hline$K \alpha_{1 a}$ & 1.540596 & \multicolumn{2}{|c|}{57.07} & 2.855 & \\
\hline$K a_{1 \mathrm{~b}}$ & 1.541058 & \multicolumn{2}{|c|}{7.64} & 3.813 & \\
\hline$K a_{2 \mathrm{a}}$ & 1.544410 & \multicolumn{2}{|c|}{25.38} & 3.376 & \multirow{2}{*}{3.557} \\
\hline$K \alpha_{2 \mathrm{~b}}$ & 1.544721 & \multicolumn{2}{|c|}{8.31} & 4.435 & \\
\hline$\Sigma$ Intensity & & \multicolumn{2}{|c|}{100.00} & & \\
\hline
\end{tabular}

With reference to the values of the relative dispersion $\Delta \lambda / \lambda$ given in Table 1 for $\mathrm{Cu} K \alpha_{1}$ and $\mathrm{Cu} K \beta$, respectively, on can calculate the difference of the resolution, if the $X$-ray's would radiate from a point source, scattered by an ideal monochromator and detected at a distance of $B=355(\mathrm{~mm})$ with an image plate detector (Figure 1). This is the only relevant variable, if one compares application of both wavelengths. Given the Bragg angle $\theta_{\mathrm{M}}$ of a $\mathrm{Ge}(111)$ monochromator, the full width at half maximum power $\Delta s(\mathrm{~mm})$ respectively $\Delta \mathcal{E}\left({ }^{\circ}\right)$ on the detector in subtractive transmittance setting can be calculated for different angles $\psi$ (Figure 1) according to

$$
\Delta s=B \cdot \frac{\mathrm{d} \lambda}{\lambda} \cdot \frac{\tan \left(\theta_{M}\right)}{\cos (\psi)}
$$

Calculations of the reflection widths according to Equation (1) were summarized in Table 2.

The relative enhancement of the $\mathrm{Cu} K \beta$ line width by only $0.0032\left(^{\circ}\right)$ in contrast to the $\mathrm{CuK \alpha _{1 }}$ one is a further argument for its possible use for $X$-ray powder diffraction.

\section{Monochromator Construction}

In case of $\mathrm{Cu} K \beta$ primary radiation an cylindrically bent $\mathrm{Ge}(111)$ monochromator is best suited to focus the secondary radiation diffracted from the sample onto the image plate detector. Table 3 summarizes the data needed to construct the monochromator from a single crystal piece of Ge cut along (111) and taking into account a certain offset angle $\tau$. Alternatively, the data for a focusing $\operatorname{Si}(111)$ 
Table 2. Reflection width $\Delta s(\mathrm{~mm})$ as $\operatorname{FWHM}(2 \theta)$ calculated according to Equation (1).

\begin{tabular}{|c|c|c|c|c|c|c|c|}
\hline \multirow[t]{2}{*}{$X$-ray line } & \multirow[t]{2}{*}{$\Delta \lambda / \lambda$} & \multicolumn{3}{|c|}{$\Delta s(\mathrm{~mm})$} & \multicolumn{3}{|c|}{$\Delta \mathcal{E}\left({ }^{\circ}\right)$} \\
\hline & & $\psi=0^{\circ}$ & $\psi=45^{\circ}$ & $\psi=60^{\circ}$ & $\psi=0^{\circ}$ & $\psi=45^{\circ}$ & $\psi=60^{\circ}$ \\
\hline $\mathrm{Cu} K \alpha_{1}$ & 0.0002930 & 0.0220 & 0.0312 & 0.0441 & 0.00550 & 0.00779 & 0.0110 \\
\hline $\mathrm{Cu} K \beta$ & 0.0004123 & 0.0310 & 0.0438 & 0.0619 & 0.00775 & 0.01096 & 0.0155 \\
\hline Difference & 0.0001193 & 0.0090 & 0.0126 & 0.0178 & 0.00225 & 0.00317 & 0.0045 \\
\hline
\end{tabular}

Table 3. Construction data for a focusing $\mathrm{Ge}(111)$ monochromator delivering $\mathrm{Cu} K \beta$ radiation. $\mathrm{A}=X$-ray source to monochromator distance, $B=$ Focal line to monochromator distance, $\theta_{\mathrm{M}}=$ Bragg angle of the monochromator, $\tau=$ Angle between (111) reciprocal planes and cylindrical surface of the monochromator (see Figure 1).

\begin{tabular}{ccc}
\hline Monochromator crystal & Ge [6] & Si [7] \\
\hline$d_{111}(\AA)$ & 3.26659 & 3.13560 \\
$A=\mathrm{SM}=2 r \cdot \sin \left(\theta_{\mathrm{M}}-\tau\right)(\mathrm{mm})$ & 120 & 120 \\
$B=\mathrm{FM}=2 r \cdot \sin \left(\theta_{\mathrm{M}}+\tau\right)(\mathrm{mm})$ & 355 & 355 \\
$\tan \tau=[(B-A) /(B+A)] \cdot \tan \left(\theta_{\mathrm{M}}\right)$ & & \\
$\mathrm{Cu} K \beta \operatorname{radiation} \lambda(\AA)$ & & 1.39225 \\
$\theta_{\mathrm{M}}\left(^{\circ}\right)$ & 12.304 & 12.827 \\
$\tau\left(^{\circ}\right)$ & 6.159 & 8.295 \\
$r(\mathrm{~mm})$ & 560.48 & 492.57 \\
$2 r(\mathrm{~mm})$ & 1120.96 & 985.14 \\
\hline
\end{tabular}

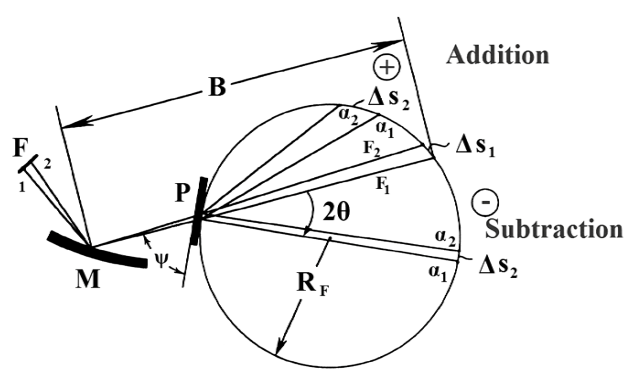

Figure 1. Effect of chromatic dispersion in the $\psi=45^{\circ}$ subtractive transmittance setting [8]. $\mathrm{F}$ = tube focus, $\mathrm{M}=$ monochromator, $\mathrm{P}=$ sample, $R_{F}=$ radius of the focusin $g$ circle, $B$ = distance between monochromator and focal line on the $I P, \Delta s=$ reflection's FWHM $(\mathrm{mm})$.

crystal monochromater were calculated.

Four steps are needed to produce a cylindrically bent single crystal monochromator [1]:

1) Elastic bending of the asymmetrically cut $\mathrm{Ge}(111)$ single crystal plate $(40 \times$ $20 \times 0.6 \mathrm{~mm}$ ) to a cylinder radius of $2 r=1120.96 \mathrm{~mm}$. This is accomplished with the aid of a curved specimen holder made of an air-permeable sintered special 
bronze that sucks the plate under vacuum.

2) Lapping of the mounted crystal to a plane surface with subsequent polishing, using an aqueous slurry containing $\alpha$-alumina with particle grain size of about $0.05 \mu \mathrm{m}$ to remove the distorted surface layer.

3) Inserting the crystal plate in a brass jig, clamped by Teflon guide ways and bent thoroughly with half the radius of curvature $(r=560.48 \mathrm{~mm})$ in the opposite direction.

4) Inserting this crystal holder in a safe housing with facilities for final crystal adjustment and primary beam shutters (for instant commercially available $\mathrm{Hu}$ ber 611 housing).

This sophisticated construction procedure was first invented in 1995 by the present author in cooperation with $H$. Lindner (University of Regensburg), and advanced applied by W. Hofmann in his dissertation [2].

\section{Resolution of a Ge(111) Monochromator}

A comparative measurement of the $\operatorname{FWHP}(2 \theta)$ between $\mathrm{Cu} K \alpha_{1}$ and $\mathrm{Cu} K \beta$ radiation suggest the application of the latter one, too. The intensity distribution of the $\mathrm{Ge}(111)$ reflection can be recorded with removed sample in the symmetrical setting position of the Guinier diffractometer behind an attenuation filter to guarantee the linear response of the IP detector. The skillful setting of beam shutters may help to eliminate mainly the $\mathrm{K} \beta$ contribution (Table 1 ) at the low energy shoulder of the $\mathrm{Cu} K \beta$ radiation to deliver an even smaller $\operatorname{FWHM}(2 \theta)$.

Preliminary results were done with the aid of our double-radius Guinier diffractometer using a fine-focus copper tube [2] [9]. They are displayed in Figure 2. However, the used monochromator was not optimized for $\mathrm{Cu} K \beta$ radiation, but for the $\mathrm{Cu} K \alpha_{1}$ one. The experimentally determined $\operatorname{FWHM}(2 \theta)=0.059^{\circ}$ for $\mathrm{Cu} K \beta$ can be reduced considerably by using a micro-focus tube, a monochromator specialized according to Table 3, and an optimized Soller slit. An estimate delivers $\operatorname{FWHM}(2 \theta) \leq 0.04^{\circ}$ for $\mathrm{Cu} K \beta$. The beam intensity is reduced by a factor of $<3$ compared to the $\mathrm{Cu} K \alpha_{1}$ result. Because the recording of an excellent $X$-ray powder pattern for Rietfeld structure determination is still not routine, the measurement time should not be the limiting factor.

Normally, the powder pattern is taken in the $\psi=45^{\circ}$ transmittance setting of subtractive chromatic dispersion (Figure 1), where the contributions to the reflection width of the monochromator and the sample successively compensate in the foremost part of the record, but increases in the region of $2 \theta>2 \theta_{c}$. The difference $\Delta s(\mathrm{~mm})$ on the focal circle yields [10]

$$
\Delta s=\left|R_{F} \cdot \frac{\mathrm{d} \lambda}{\lambda}\left(\frac{B}{R_{F}} \cdot \frac{\tan \left(\theta_{M}\right)}{\cos (\psi)}-4 \cdot \tan (\theta)\right)\right|
$$

Calculations for the normally used $\psi=45^{\circ}$ setting are displayed in Figure 3 by contrast to the $60^{\circ}$ one. The $\psi=60^{\circ}$ setting seems to be fortunate, because one can cope with the broadening of a few reflections in the front area of the 

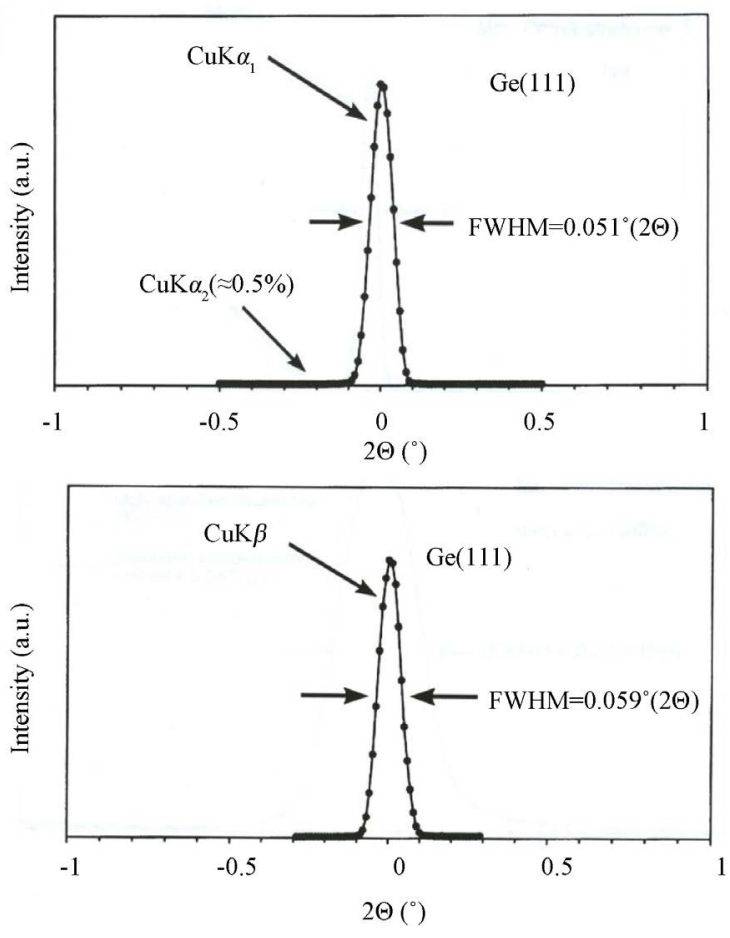

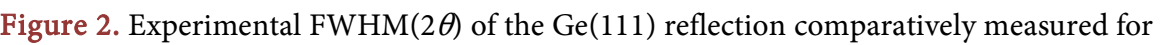
$\mathrm{Cu} K \alpha_{1}$ and $\mathrm{Cu} K \beta$ radiation according to [2]. However, only a fine-focus tube was available, and the used monochromator was not optimal for $\mathrm{Cu} K \beta$ radiation.

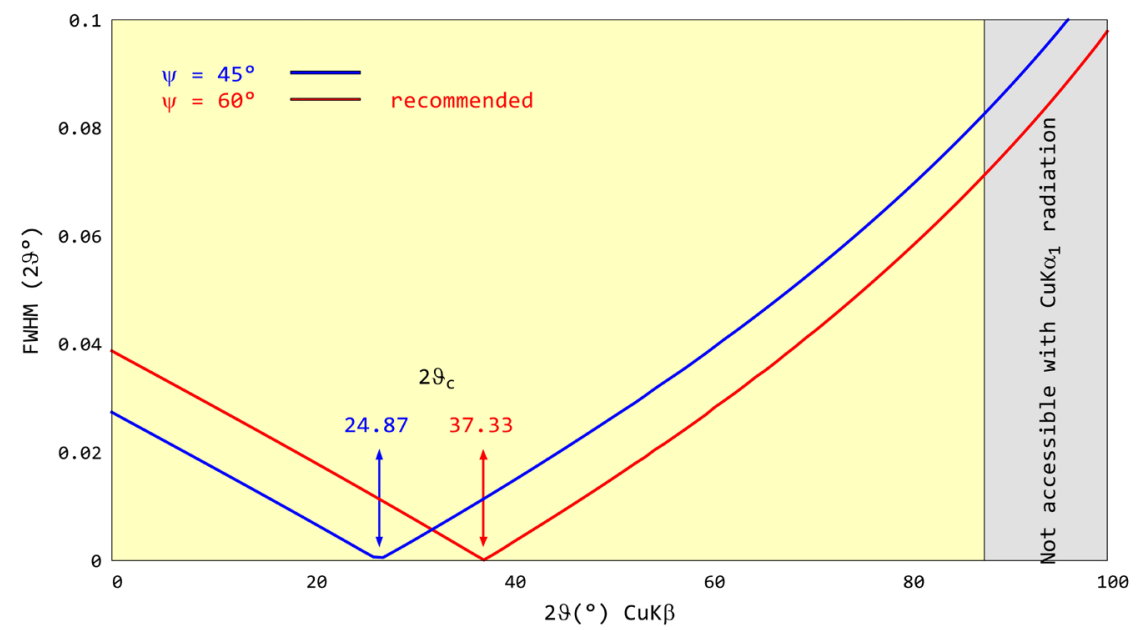

Figure 3. Reflection width displayed for two different camera settings of subtractive chromatic dispersion. $2 \theta_{c}$ represents the angle at which monochromator and sample contribution to the $\mathrm{FWHM}(2 \theta)$ compensates.

pattern and then have many reflections with a smaller width in the rear part of the pattern.

\section{The Double-Radius Guinier Diffractometer with Image Plate Detector and 6-Fold Sample Changer}

Our activities to construct $X$-ray diffraction equipment began at the University 
of Regensburg in 1980 with the first automated Guinier diffractometer with a counter tube radiation detector, state of the art at that time [11]. This arrangement was supplemented with a second counter to reduce the measurement time [12]. Later at the TU Clausthal, the idea for the construction of a double-radius Guinier camera with $I P$ detector and 6-fold sample changer was realized before others took similar action (Figure 4) [1] [2] [9]. The author of this article joked in front of visitors to his laboratory that he would not be surprised when others possible patent claims could circumvent, if they did not construct a sample changer with six but four or even eight places, which was then done, what a coincidence, quickly afterwards by a German company. However, the crystallographic community is more familiar with our double-radius Gandolfi camera with imaging plate detector and sophisticated radiation detection with a stripe by stripe read out technique, illustrated in Figure 5 [13]. Very recently, a smart multipurpose $X$-ray camera on the basis of the Gandolfi technique was proposed by the author for simultaneous measurement of powder-like diffraction and fluorescence radiation of a minute single crystal [14]. In the following chapter some practical advices are given, and the scattering angle calibration is described in detail.

\section{Scattering Angle Calibration and Practical Advices}

Typical results of a calibration of the scattering angle $2 \theta$ were displayed exemplarily for $\mathrm{Cu} \mathrm{Ka}_{1}$ in Figure 6 . For routine use we chose the combination of two standards: Ag-behenate [15], covering the foremost part of the pattern, and cubic $\mathrm{LaB}_{6}[16]$. The special curve that shows the deviations from the calculated

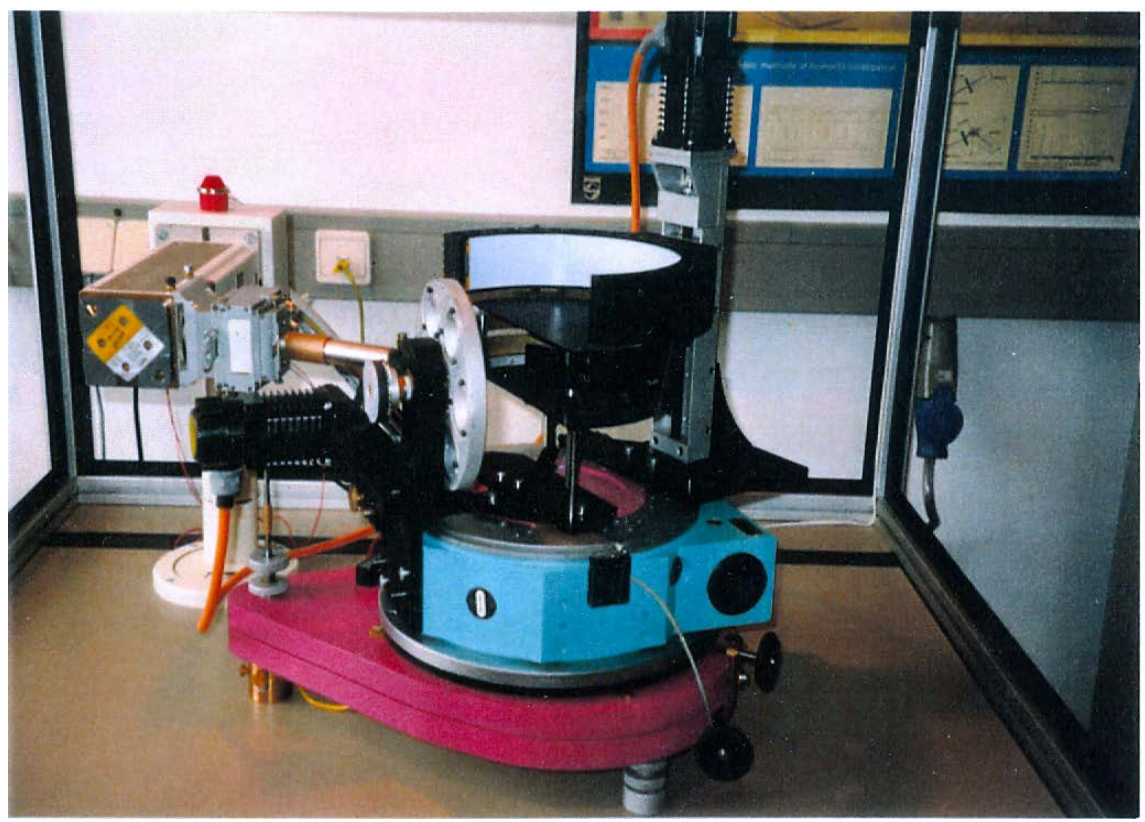

Figure 4. Highly precise double-radius Guinier camera with $I P$ detector and 6-fold sample changer adapted to a focusing $\mathrm{Ge}(111)$ monochromator on a micro-focus $\mathrm{Cu}$ tube, as constructed in our laboratory already in 1996 [1] [9]. 


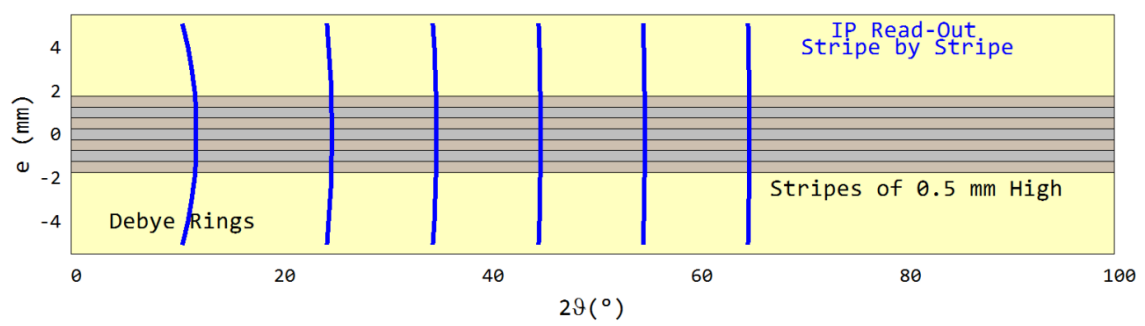

Figure 5. Proposal for an $I P$ stripe by striperead-out routine.

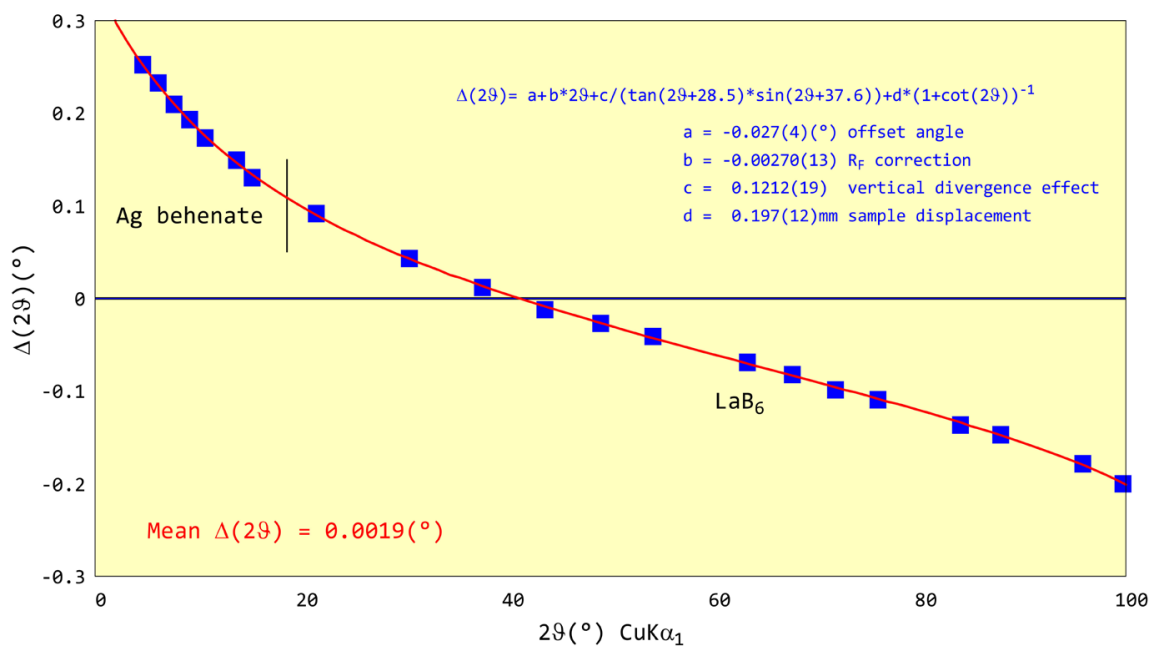

Figure 6. Typical calibration curve of $\Delta 2 \theta$ versus $2 \theta$ (calculated) using four fit parameters. Standards: Ag behenate $d_{001}=58.380(3) \AA[15], \mathrm{LaB}_{6} a=4.15695(6) \AA$ (SRM 660) [16]. The found deviations were used to adjust the affected equipment to reach a shallow calibration profile.

$2 \theta$ values is caused by different shift contributions, which can be corrected quite well by applying analytic expressions. The vertical ray divergence leads to the superposition of Debye rings generated at a different high of the irradiated sample resulting in a pronounced $2 \theta$ shifts to smaller values even in the low angle region. This shift can be reduced by an adjusted vertical primary beam entrance slit. However, a strong correlation to the offset angle $2 \theta_{0}$ still remains. Also the horizontal primary beam divergence should be limited by $1-2 \mathrm{~mm}$ slits to reduce the width of the reflection. Soller slits before the plain sample should not be constructed by vertical stacks of stainless steel sheets but by cleaved muscovite sheets or fused silica cover glasses coated with evaporated gold and repeatedly arranged at a distance of $0.2 \mathrm{~mm}$ as described before [1]. This action prevents fluorescence radiation by iron.

The distance of the sample on the focusing circle (Figure 2) may be controlled first by using specimen holders finished by lapping to a thickness that deviation less than $1 \mu \mathrm{m}$, and by controlling the specimen thickness to only few $\mu \mathrm{m}$ of thickness, always using the same mylar foil package. Nevertheless, it remains a small scattering angle deviation, because the flat specimen has not the curvature of the focal circle, further by angle dependent absorption in the sample and in 
the $I P$ detector, respectively.

The asymmetrical reflection profiles in the foremost part of the pattern as well as the shift of the scattering angles to lower values can be scaled down, if the read-out of the pattern would be done stripe by stripe each of high $\Delta e=0.5 \mathrm{~mm}$ (Figure 5). Then the intensities can be merged after their projection along the Debye ring onto the equator. This procedure was successfully applied by the author using five such stripes to collect data from a Gandolfi pattern [13].

Given the radius of curvature $r_{\mathrm{e}}(2 \theta)(\mathrm{mm})$ of the Debye cone on the Guinier camera equator,

$$
r_{\mathrm{e}}(2 \theta)=2 R_{\mathrm{F}} \cdot \tan (2 \theta) \cdot \sin (2 \theta+\psi),
$$

the angle $2 \theta_{\mathrm{e}}\left({ }^{\circ}\right)$ measured at the high $e$ above the equator yields

$$
\begin{gathered}
2 \theta_{\mathrm{c}}\left({ }^{\circ}\right)=2 \theta_{\mathrm{o}}-\Delta \varepsilon \\
\text { where } \Delta \varepsilon\left(^{\circ}\right)=\Delta s / 4=\left(r_{\mathrm{e}}(2 \theta)-\sqrt{\left(r_{\mathrm{e}}(2 \theta)^{2}-e^{2}\right)}\right) / 4 .
\end{gathered}
$$

In addition, if one possibly finds intensity variations on the Debye Scherrer rings caused by a texture of the sample, one would be able to analyze its origin with the aid of such stripe by stripe read out and correct the intensities accordingly.

\section{Conclusion}

Arguments for routine use of $\mathrm{Cu} K \beta$ radiation for the crystal structure determination from powders by the Rietfeld method were summarized, using the Guinier method in a special setting of subtractive chromatic dispersion. A self-constructed cylindrically bent $\mathrm{Ge}(111)$ monochromator focuses $\mathrm{Cu} K \beta$ radiation onto a high-resolution $I P$ detector. The shorter wavelength in comparison to the $\mathrm{Cu} K \alpha_{1}$ radiation allows recording of about $35 \%$ more reflections in the accessible reciprocal space in a reasonable measuring time without significantly decreased resolution by using a micro-focus $X$-ray tube. Unwanted fluorescence radiation can be simply discriminated as enhanced background due to the large dynamical range of the $I P$ detector used. However, this proposed in-house equipment applying $\mathrm{Cu} K \beta$ radiation may be quite ambitious in competition to the use of synchrotron radiation. The application of a liquid-gallium-metal-jet $X$-ray source with maximum power load and a wavelength of $\lambda\left(G a K \alpha_{1}\right)=$ $1.34013 \AA$ may be a more expensive laboratory alternative in future. It is recommended to complete the needed atomic scattering factor tables for $\mathrm{Cu} K \beta$ and for $\mathrm{Ga} K \alpha_{1}$ radiation, respectively, in the International Tables for $X$-ray Crystallography.

\section{Acknowledgements}

This work was supported several times by the German Research Foundation (DFG). Once again the author thanks H. Lindner (University of Regensburg) and K. Schröder (TU Clausthal) for technical help. 


\section{Conflicts of Interest}

The author declares no conflicts of interest regarding the publication of this paper.

\section{References}

[1] Otto, H.H. and Hofmann, W. (1996) Construction of a Double Radius Guinier Diffractometer Using MoKa $\alpha_{1}$ Radiation and a One- or Two-Dimensional Detection System. Journal of Applied Crystallography, 29, 495-497. https://doi.org/10.1107/S0021889896005377

[2] Hofmann, W. (2000) Höchstauflösende Pulverdiffraktometrie mit Hilfe einer neu entwickelten Guinier-Bildplattenkamera. Dissertation, TU Clausthal.

[3] Otendal, M., Tuohimaa, T., Vogt, U. and Hertz, H.M. (2008) A 9 keV Electron-Impact Liquid-Gallium-Jet X-Ray Source. Review of Scientific Instruments, 79, Article ID: 016102. https://doi.org/10.1063/1.2833838

[4] Hazell, A.C. (1967) Anomalous Scattering Corrections for X-Rays $\beta$-Radiations. Acta Crystallographica, 23, 1096-1098. https://doi.org/10.1107/S0365110X67004323

[5] Deutsch, M., Hölzer, Härtwig, G., Wolf, J., Fritsch, M. and Förster, E. (1995) Ka and K X X-Ray Emission Spectra of Copper. Physical Review A, 51, 283-296. https://doi.org/10.1103/PhysRevA.51.283

[6] Baker, J.F.C. and Hart, M. (1975) An Absolute Measurement of the Lattice Parameter of Germanium Using Multiple-Beam X-Ray Diffractometry. Acta Crystallographica, A31, 364-367. https://doi.org/10.1107/S0567739475000769

[7] Kessler, E.G., Henins, A., Deslattes, R.D., Nielsen, L. and Arif, M. (1994) Precision Comparison of the Lattice Parameters of Silicon Monocrystals. Journal of Research of the National Institute of Standards and Technology, 99, 1-18. https://doi.org/10.6028/jres.099.002

[8] Zevin, L.S. and Kimmel, G. (1995) Quantitative X-Ray Diffractometry. Springer, New York. https://doi.org/10.1007/978-1-4613-9535-5

[9] Otto, H.H. (1996) Double-Radius Guinier Diffractometer with IP Detector. ResearchGate, Berlin.

[10] Hofmann, E.G. and Jagodzinski, H. (1955) Eine neue, hochauflösende Röntgenfeinstruktur-Anlage mit verbessertem, fokussierenden Monochromator und Feinfokusröhre. Zeitschrift für Metallkunde, 46, 601-609.

[11] Otto, H.H. (1979) Kristallchemische und kristallographische Untersuchungen an Germanaten und anderen Verbindungen des Bleis. Arbeitsbericht zum DFG-Projekt AZ Ot 65/1. https://www.researchgate.net/

[12] Otto, H.H., Baltrusch, R. and Schröder, K. (1996) Erfahrungen mit einem Guinier-Diffraktometer mit zwei Zählrohren. Beihefte zu European Journal of Mineralogy, 8, 204.

[13] Otto, H.H., Hofmann, W. and Schröder, K. (2002) A Double-Radius Gandolfi X-Ray Camera for the Generation of Powder-Like Diffractograms of Small Single Crystals, Using an Imaging Plate Detector. Journal of Applied Crystallography, 35, 13-16. https://doi.org/10.1107/S0021889801016594

[14] Otto, H.H. (2017) A Smart Multi-Purpose X-Ray Camera Proposed for Simultaneous Measurement of Powder-Like Diffraction and Fluorescence Radiation of a Minute Single Crystal. International Journal of New Technologies in Science and Engineering, 4, 10-13. 
[15] Huang, T.C., Toraya, H., Blanton, T.N. and Wu, Y. (1993) X-Ray Powder Diffraction Analysis of Silver Behenate, a Possible Low-Angle Diffraction Standard. Journal of Applied Crystallography, 26, 180-184. https://doi.org/10.1107/S0021889892009762

[16] Rasberry, S.D. (1989) Standard Reference Material 660, Certificate of Analysis. National Institute of Standards \& Technology, 1-3. 